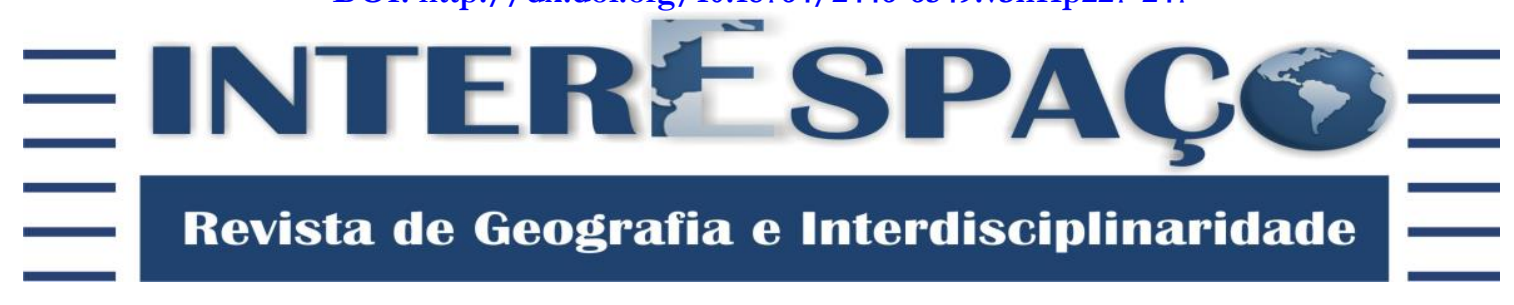

\title{
FAMÍLIA E ESCOLA: \\ Parceiras no desenvolvimento moral das crianças
}

FAMILY AND SCHOOL: partners in children's moral development

FAMILIA Y ESCUELA: asociaciones en el desarrollo moral de los niños

\begin{abstract}
Rosana Mendes de Matos Privado
Especialista em Psicologia da Educação pela Universidade Estadual do Maranhão - UEMA. Licenciada em Pedagogia pelo Instituto de Ensino Superior - IESF. Coordenadora Pedagógica da Educação Infantil no Município de Grajaú - MA. rosana_privado@hotmail.com

\section{Neusani Oliveira Ives-Felix}

Doutoranda em Antropologia e Mestra em Educação pela Universidade Federal do Pará - UFPA. Professora Assistente A do Curso de Licenciatura em Ciências Naturais/Química da Universidade Federal do Maranhão - UFMA/Câmpus de Grajaú. neusanives2@gmail.com
\end{abstract}

Recebido para avaliação em 02/03/2017; Aceito para publicação em 20/04/2017.

\begin{abstract}
RESUMO
Contribuir para o desenvolvimento moral infantil tem sido um desafio à sociedade, e a relação família e escola é de suma importância para o desenvolvimento do juízo moral nos infantes. Nesse sentido, a investigação teve o intuito de responder aos seguintes questionamentos: de que forma a família e a escola, enquanto parceiras, têm contribuído para o desenvolvimento da autonomia e democracia quanto às regras e punições em crianças pequenas? Quais atitudes podem fortalecer o vínculo entre família e escola a fim de contribuírem com o desenvolvimento do juízo moral dos infantes? É importante frisar que a pesquisa investiga pais e professores de crianças com faixa etária entre 3 e 5 anos, que frequentam a Pré-Escola Aurila Barros, localizada no Conjunto Habitacional Frei Alberto Beretta, no município de Grajaú/MA. A compreensão sobre como se dá a moral em alunos pré-escolares, dentro dos estudos relacionados à Psicologia Moral, encontrou respaldo teórico em Piaget (1994) e Kohlberg (apud BIAGIO, 2002), bem como autores como La Taille (1992), Montoya (2004), Sampaio (2007), Munari (2010), entre outros, com vistas a corroborar com a pesquisa empírica, que também contou com a entrevista aplicada a vinte pais e seis professores, os quais descreveram em questões subjetivas suas ações e preocupações no concernente aos seus papéis no desenvolvimento moral dos pequenos, confirmando que, apesar de a escola compreender a sua função no desenvolvimento da moralidade infantil, os pais ainda encontram-se confusos quanto a sua cooperação efetiva.

Palavras-chave: Juízo Moral; Pré-Escola; Psicologia Moral.
\end{abstract}

\section{ABSTRACT}

Contributing to child moral development has been a challenge to society, and the family and school relationship is of paramount importance for the development of moral judgment in infants. In this sense, the research aimed to answer the following questions: How have the family and the school, as partners, contributed to the development of autonomy and democracy regarding the rules and punishments of young children? What attitudes can strengthen the bond between family and school in order to contribute to the development of moral judgment of infants? It is important to emphasize that the research investigates parents and teachers of children aged 3 to 5 years attending 


\section{Dossiê: Diálogos interdisciplinares em Psicologia da Educação \\ | Família e escola: parceiras no desenvolvimento moral das crianças |}

| Rosana Mendes de Matos Privado | Neusani Oliveira Ives-Felix |

the Aurila Barros Pre-School, located in the Frei Alberto Beretta Housing Set, on the outskirts of the municipality of Grajaú/MA. Moria's understanding of how morality occurs in preschoolers within studies related to Moral Psychology has found theoretical support in Piaget (1994) and Kohlberg (apud BIAGIO, 2002), as well as authors such as La Taille (1992), Montoya (2004), Sampaio (2007), Munari (2010), among others, in order to corroborate the empirical research, which also had the interview applied to twenty parents and six teachers, who described in subjective questions their actions and concerns in the concerning their role in the moral development of the children, confirming that although the school understands its role in the development of child morality, parents still find themselves confused as to their effective cooperation.

Keywords: Moral Judgment; Preschool; Moral Psychology.

\section{RESUMEN}

Contribuir al desarrollo moral infantil ha sido un desafío a la sociedad, y la relación familia y escuela es de suma importancia para el desarrollo del juicio moral en los infantes. En este sentido, la investigación tuvo el propósito de responder a los siguientes cuestionamientos: ¿de qué forma la familia y la escuela, como socios, han contribuido al desarrollo de la autonomía y democracia en cuanto a las reglas y castigos en niños pequeños? ¿Cuáles actitudes pueden fortalecer el vínculo entre familia y escuela a fin de contribuir con el desarrollo del juicio moral de los infantes? Es importante resaltar que la investigación investiga padres y profesores de niños con edades entre $3 \mathrm{y}$ 5 años, que frecuentan la Pre-Escuela Aurila Barros, ubicada en el Conjunto Habitacional Frei Alberto Beretta, en el municipio de Grajaú/MA. La comprensión sobre cómo se da la moral en alumnos preescolares, dentro de los estudios relacionados a la Psicología Moral, encontró respaldo teórico en Piaget (1994) y Kohlberg (apud BIAGIO, 2002), así como autores como La Taille (1992), Montoya (2004), Sampaio (2007), Munari (2010), entre otros, con miras a corroborar la investigación empírica, que también contó con la entrevista aplicada a veinte padres y seis profesores, los cuales describieron en cuestiones subjetivas sus acciones y preocupaciones en el tema en relación con sus papeles en el desarrollo moral de los pequeños, confirmando que, a pesar de que la escuela comprende su función en el desarrollo de la moralidad infantil, los padres todavía se confunden en cuanto a su cooperación efectiva.

Palabras clave: Juicio Moral; Preescolar; Psicología Moral.

\section{INTRODUÇÃO}

O ser humano é sociável desde o nascimento. Todo conhecimento cultural acumulado ao longo do seu desenvolvimento é fruto da socialização estabelecida no ambiente familiar, escolar e no meio social como um todo.

Para a criança, esse envolvimento social também é essencial para a apropriação de normas e valores que regem a coletividade em que está inserida. Fica, pois, claro que esse desenvolvimento não é imediatista, mas um acontecimento que ocorre durante toda a infância, sendo de suma importância pais e educadores terem conhecimento de como se dá esse processo e como está relacionado ao desenvolvimento moral do infante.

Nesse caso, surge a necessidade de apresentar um trabalho que fomente a discussão sobre a assimilação de regras e valores pelas crianças com faixa etária entre 3 e 5 anos e como a escola e a família de forma colaborativa atuam frente ao desenvolvimento moral 
Dossiê: Diálogos interdisciplinares em Psicologia da Educação

|Família e escola: parceiras no desenvolvimento moral das crianças |

| Rosana Mendes de Matos Privado | Neusani Oliveira Ives-Felix |

dos pequenos. O estudo em questão nasceu da afinidade com um projeto de autoria da escritora Ana Maura Tavares dos Anjos, aplicado pela Secretaria Municipal de Educação do Município de Grajaú em uma parceria com a Editora IPDH. O projeto tem como objetivo contribuir significativamente para o fortalecimento dos vínculos familiares entre crianças, pais ou outros responsáveis e conta com a apreciação literária de quatro livros: Miga a minhoca teimosa, Balaio de gatos, Um robô no conserto e Teco, o tatuzinho (ANJOS, 2014).

Contribuir para o desenvolvimento moral infantil tem sido um desafio à sociedade atualmente. Os pais, em sua grande maioria, têm atribuído à escola a responsabilidade da educação moral de seus filhos, e a escola culpa os pais por não atuarem ativamente na vida dos educandos, tornando-se assim um "jogo de empurra", no qual todos os envolvidos se eximem da responsabilidade de contribuir com o desenvolvimento moral das crianças.

Desse modo, é preciso dar respostas às seguintes problemáticas: de que forma a família e a escola, enquanto parceiras, favorecem o desenvolvimento da autonomia e democracia quanto às regras e punições em crianças pequenas? Quais atitudes podem fortalecer o vínculo entre família e escola a fim de contribuírem com o desenvolvimento do juízo moral dos infantes?

Com o intuito de responder a esses questionamentos, a fundamentação teórica assenta-se na Psicologia Moral, mais notadamente em dois teóricos, os quais se complementam: Piaget (1994) e Kohlberg (apud BIAGIO, 2002), que descrevem o desenvolvimento da moral em crianças e adolescentes. Porém, a referida pesquisa, conforme delimitado no tema, estará focada em crianças entre 3 e 5 anos.

Diferentes correntes em psicologia abordam a moralidade, sob diversos pontos de vista. Em Freud (apud BIAGIO, 2002), a moralidade está explicitada no Complexo de Édipo, em que a criança se identifica com o genitor do mesmo sexo, assimilando suas proibições e seus valores morais. Para os primeiros behavioristas, a consciência moral coincidia com fenômenos da resistência à extinção. Nesse sentido, a criança, ao ser punida várias vezes por um comportamento indesejado, sofria a extinção do comportamento recriminado, bem como inversamente o reforço ao comportamento satisfatório (BIAGIO, 2002).

Tanto para a psicanálise como para os behavioristas a educação moral é algo exterior, sendo internalizada pelo indivíduo a ponto de ser considerado algo intrínseco à própria pessoa. Contrapondo-se a esse pensamento, surge o construtivismo de Piaget 
Dossiê: Diálogos interdisciplinares em Psicologia da Educação

|Família e escola: parceiras no desenvolvimento moral das crianças |

| Rosana Mendes de Matos Privado | Neusani Oliveira Ives-Felix |

(BIAGIO, 2002) e o enfoque cognitivo-evolutivo de Kohlberg, compreendendo o sujeito como agente do processo moral.

Apesar de os construtivistas criticarem as teorias comportamentalistas, é necessário considerá-las complementares, pois a perspectiva da teoria comportamental é de suma importância no que diz respeito ao desenvolvimento moral de crianças, não por causa do extremismo da extinção de um determinado comportamento, mas para que se possa assimilar as regras e os valores.

Embora Piaget (1994) compreenda a coação adulta como problema, que repercute, inclusive, na aprendizagem, ele defende que as regras e os valores precisam ser transmitidos a crianças pequenas tal qual essas são e da forma como as vivemos, para que, posteriormente e com amadurecimento psicológico e cognitivo, possam interpretá-las conscientemente na fase entre os 7 e 11 anos (operações concretas).

Segundo Kolberg (apud BIAGIO, 2002) e Piaget (1994), o desenvolvimento moral de uma pessoa é invariante e universal a todas as culturas, mas o que seria juízo moral? Entende-se por juízo moral na criança o conjunto de regras que em geral lhe é instituído pela maioria dos adultos, que é a essência da moralidade, bem como está relacionado ao respeito que ela nutre por tais regras (PIAGET, 1994).

Com vistas a fundamentar a referida pesquisa, atentou-se para a seguinte problemática: $O$ que pais e professores necessitam levar em consideração no desenvolvimento moral das crianças em fase pré-escolar? Assim, esta pesquisa teve como objetivo geral: analisar o que pais e professores instituem no relacionamento com seus filhos e/ou alunos no concernente ao desenvolvimento do juízo moral dos infantes, e se há a preocupação com a potencialização da autonomia frente às regras e punições em crianças com faixa etária entre 3 e 5 anos.

Convém delimitar os objetivos específicos da presente pesquisa, que são: descrever os procedimentos utilizados pelos pais e educadores na educação moral dos infantes; relatar as noções que pais e professores e educandos têm quanto ao respeito como sentimento essencial à obtenção de noções morais; verificar de que forma a autonomia resultante de uma moral relacionada ao respeito mútuo e das relações de cooperação tem sido valorizada na formação moral dos pequenos; compreender como família e escola se relacionam e como ambas se posicionam acerca do desenvolvimento moral dos pequenos.

Faz-se pertinente que tanto a família quanto a escola estreitem cada vez mais os seus laços, a fim de que, unidas, possam contribuir para o desenvolvimento moral dos 
Dossiê: Diálogos interdisciplinares em Psicologia da Educação

|Família e escola: parceiras no desenvolvimento moral das crianças |

| Rosana Mendes de Matos Privado | Neusani Oliveira Ives-Felix |

pequenos, sob o escopo de que não sejam meras marionetes num emaranhado de regras e normas, mas que tenham autonomia para gerenciar suas ações de forma consciente.

Por se tratar de uma pesquisa empírica, o presente artigo apresenta em seu primeiro tópico a introdução do estudo, no qual se aborda a justificativa, o problema, os objetivos, bem como a sequência dos assuntos a serem abordados. O segundo tópico trata da teoria sobre o assunto em questão, tendo como autores principais Piaget (1994) e Kohlberg (apud BIAGIO, 2002), fundamentando sobre como o desenvolvimento do juízo moral da criança se estrutura. Já o terceiro tópico expõe a metodologia utilizada para o desenvolvimento da pesquisa. No quarto tópico, apresenta-se a análise dos resultados coletados e, por fim, no quinto tópico, conclui-se o tema exposto com as considerações finais.

\section{METODOLOGIA}

\section{Caracterização da Pré-Escola Aurila Barros}

A escola escolhida para o desenvolvimento do referido estudo localiza-se em uma comunidade relativamente nova no Município de Grajaú, advinda do Programa Federal Minha Casa, Minha Vida. É um conjunto habitacional novo e periférico, cujos moradores se encontram vulneráveis socialmente, devido à exposição a diversas situações de risco, a saber, violência, uso de drogas e outras situações que impedem o ser humano de viver com respeito e dignidade.

É nesse contexto que a Pré-Escola Aurila Barros está localizada; é um espaço que outrora fora de uso dos trabalhadores responsáveis pela construção das casas. Adaptada, por uma iniciativa municipal, contém quatro salas de aula, uma secretaria, banheiros femininos e masculinos, uma cantina e um pátio pequeno.

A Pré-Escola Aurila Barros iniciou suas atividades no ano de 2013, com as adaptações básicas para seu funcionamento. Atualmente, embora tenha a mesma estrutura física, suas quatro salas de aula e secretaria estão devidamente climatizadas. O nome da instituição é uma homenagem a uma educadora do município de Grajaú, que é mãe do antigo proprietário e fundador do Loteamento Frei Alberto Beretta.

No momento da pesquisa, a escola contava com 14 (quatorze) funcionários entre auxiliares administrativos, vigilantes, serviços gerais e professores. Possui, ainda, em seu corpo de funcionários, um diretor e um coordenador.

Ofertando o ensino para crianças de três a cinco anos de idade e atendendo exclusivamente aos pequenos da comunidade em que está inserida, o corpo discente da 
Dossiê: Diálogos interdisciplinares em Psicologia da Educação

|Família e escola: parceiras no desenvolvimento moral das crianças |

| Rosana Mendes de Matos Privado | Neusani Oliveira Ives-Felix |

escola no corrente ano é formado por 80 alunos, distribuídos nos turnos matutino e vespertino.

\section{Procedimentos metodológicos}

Para realizar a análise, é pertinente mencionar que “[...] não existem normas que identifiquem os procedimentos a serem adotados no processo de interpretação dos dados [...]" (NEVES; DOMINGUES, 2007, p. 102). Dessa forma, faz-se imperativo, enquanto pesquisa, cuidar para que as interpretações a serem feitas sejam neutras e baseadas tanto em dados empíricos quanto na fundamentação teórica revisada ao longo do estudo.

Quanto ao tipo de pesquisa a ser desenvolvida, a sua abordagem é de cunho empírico. De acordo com Demo (1995, p. 133), “[...] a questão da empiria coloca, antes da coleta e do uso do dado empírico, problemas teóricos, porque um dado não fala por si, mas pela boca de uma teoria”. Assim, tem-se a teoria pautada em Piaget (1994) e Kohlberg (apud BIAGIO, 2002), bem como autores como La Taille (1992), Montoya (2004), Sampaio (2007), Munari (2010), entre outros. Além disso, faz-se uma comparação entre a teoria explicitada e as ações de pais e professores frente ao desenvolvimento moral das crianças atendidas pela Pré-Escola Aurila Barros.

É pertinente enfatizar que, embora se apresente de forma qualitativa, a pesquisa também foi interpretada através dos números, uma prática defendida por Triviños (1987 apud NEVES; DOMINGUES, 2007, p. 56), segundo o qual:

A análise qualitativa pode ter apoio quantitativo, contudo geralmente se omite a análise estatística ou seu emprego não é sofisticado. Admite-se que os dados numéricos de uma abordagem qualitativa também possuam significados agregados, sendo, portanto, passíveis de interpretação.

Sobre os instrumentos de coletas de dados, utilizou-se a entrevista com questões estruturadas, aplicada para 20 (vinte) pais, de um total de 65 (sessenta e cinco), e três professores das classes do maternal (crianças com 3 anos), infantil I (crianças com 4 anos) e infantil II (crianças com 5 anos). A fim de preservar a identidade dos participantes, optouse por usar letras que pudessem representar cada um: A, B e C.

\section{RESULTADOS E DISCUSSÃO}

\section{O desenvolvimento do juízo moral na criança}


Dossiê: Diálogos interdisciplinares em Psicologia da Educação

| Família e escola: parceiras no desenvolvimento moral das crianças |

| Rosana Mendes de Matos Privado | Neusani Oliveira Ives-Felix |

Através das regras que regem a vivência humana em sociedade, dá-se o ingresso da criança à moralidade, ingresso esse permeado de conflitos, uma vez que não há completa ligação entre a realidade moral com o inatismo humano. O que está ligado à psicobiologia do indivíduo são suas disposições afetivas como os componentes do respeito (empatia e medo), a imitação, o instituto de subordinação social, a afeição etc. Entretanto, ao deixar tais mecanismos de forma inata, sem as disciplinas normativas instituídas pelo convívio em sociedade, "[...] essas forças puramente inatas permaneceriam anárquicas: fonte dos piores excessos" (MENIN, 1996, p. 3).

Faz-se necessário mencionar práticas desenvolvidas outrora. Por exemplo, "para os primeiros behavioristas [...] a consciência ou moralidade poderia ser equiparado ao fenômeno de resistência à extinção" (BIAGIO, 2002, p. 20). Nesse sentido, pode-se afirmar que de tanto ser punida por um determinado comportamento indesejado, a criança deixa de praticá-lo, e de outro modo o comportamento desejado é reforçado de forma positiva. Esse tipo de prática enfatiza que a moral é algo externo, e que é internalizado pelo sujeito, fazendo então parte dele. No entanto, com o enfoque construtivista de Piaget (1994) e a perspectiva cognitivo-evolutivo de Kohlberg (apud BIAGIO, 2002), surge um homem responsável por seu desenvolvimento moral, visto que é agente ativo no meio social (BIAGIO, 2002).

Com base nessas comparações procedimentais, pode-se enfatizar o entendimento de Piaget (1994, p. 23) sobre moral, para o qual " [...] toda moral consiste num sistema de regras, e a essência de toda moralidade deve ser procurada no respeito que o indivíduo adquire por essas regras". Com efeito, não basta que as crianças sejam constantemente castigadas, a fim de se obter um determinado comportamento, é preciso que tenham consciência da importância das regras para haver um convívio harmonioso no meio social.

Conforme Zagury (2011, p. 48-50), o comportamento infantil não é algo inato, a criança não nasce sabendo sobre certas normas do convívio social, ela externiza em "[...] um saber adquirido, uma aprendizagem social". Na verdade, o castigo físico, de forma reiterada, reprime um comportamento que satisfaz a criança, mesmo contra a vontade dos adultos que a cercam.

Piaget (1994), em sua obra Le jugement moral chez. l'efant'", publicada em 1932, que dá início aos estudos e pesquisas em Psicologia Moral, descreve quatro estágios sucessivos da prática das regras que perpassam paralelamente ao desenvolvimento cognitivo em geral, são esses:

${ }^{1}$ Em português, o livro intitula-se "O julgamento moral da criança". 
Dossiê: Diálogos interdisciplinares em Psicologia da Educação

|Família e escola: parceiras no desenvolvimento moral das crianças |

| Rosana Mendes de Matos Privado | Neusani Oliveira Ives-Felix |

i. Primeiro estágio - aproximadamente por volta dos dois primeiros anos de vida, apresenta uma prática genuinamente motora e individual, em que a criança brinca a seu modo particular, seguindo, em parte, projeções ritualizadas;

ii. Segundo estágio - Vivenciado pelo infante entre aproximadamente os 2 aos 6 anos. É denominado de egocêntrico, por a criança receber do meio em que está inserida as regras previamente estabelecidas, considerando-as imutáveis e sagradas por serem provenientes de um adulto e/ou criança mais velha. Mesmo imitando o procedimento geral, ainda mantém atuante sua forma particular de agir;

iii. Terceiro estágio - $\mathrm{Na}$ fase chamada de cooperação nascente, surge a imprescindibilidade do controle em grupo e do fortalecimento das regras, sua mutação depende do consenso de todos os envolvidos na ação, ocorrendo por volta dos sete aos dez anos de idade;

iv. Quarto estágio - Nessa etapa, iniciada por volta dos onze ou doze anos, surge a codificação das regras. Estas são compreendidas nos seus pormenores, além de discuti-las correlacionadas ao raciocínio formal.

Piaget (1994) acreditava que a condição inicial para o desenvolvimento das regras está no ritual - imitação da criança frente a situações vivenciadas - bem como nos símbolos - instrumentos que nas mãos dos pequenos expressa o seu pensamento. Mas o ritual e o símbolo individuais não são considerados suficientes para a construção estrutural da consciência, faz-se necessário vivenciá-la na coletividade.

É fundamental acreditar que dar limites [...] é iniciar o processo de compreensão e apreensão do outro [...]. Ninguém pode respeitar seus semelhantes se não aprender quais são os seus limites - e isso inclui compreender que nem sempre se pode fazer tudo que se deseja na vida. É necessário que a criança interiorize a ideia de que poderia fazer muitas [...] das coisas que deseja - mas nem tudo e nem sempre (ZAGURY, 2011, p. 13).

A criança, no período do segundo estágio, entre 2 e 6 anos de idade, apresenta-se hedonista por natureza (ZAGURY, 2011, p. 48-50), ou seja, espontaneamente busca aquilo que lhe dá prazer. Porém, entende, através do convívio social e das pessoas adultas que lhe orientam, a importância do respeito e do cumprimento das regras, prática inúmeras vezes evitada por pais e professores por entenderem que a criança é pequena demais para compreender tais questões.

Está evidente que tal prática está amparada na obediência imposta pelo adulto, a qual deve ser compreendida ao pé da letra e acarreta uma concepção objetiva de responsabilidade. Piaget, em estudo sobre moral infantil, denomina isso de realismo moral, 
Dossiê: Diálogos interdisciplinares em Psicologia da Educação

|Família e escola: parceiras no desenvolvimento moral das crianças |

| Rosana Mendes de Matos Privado | Neusani Oliveira Ives-Felix |

que é " $[. .$.$] a tendência da criança em considerar os deveres e os valores a eles relacionados$ como subsistentes em si, independentemente da consciência e se impondo obrigatoriamente, quaisquer que sejam as circunstâncias [...]".

Mesmo havendo uma crítica sobre o realismo moral, em nossos dias, com o advento tecnológico, bem como com as mudanças no seio familiar, social e econômico, nossas crianças apresentam características totalmente diferentes das que cresceram nos séculos XIX e XX. Em vez de crianças tímidas, recuadas, reprimidas, temos crianças exploradoras, comunicativas, independentes, questionadoras. Ademais, não raras vezes, pela ausência na educação dos filhos, muitos pais acabam se tornando demasiadamente permissivos.

Facilmente se presume que o indivíduo, um ser essencialmente social, não pode ser compreendido fora desse contexto. De acordo com La Taille (1992, p. 11):

[...] o homem não social, o homem considerado como molécula isolada do resto de seus semelhantes, o homem visto como independente das influências dos diversos grupos que frequenta, o homem visto como imune aos legados da história e da tradição, este homem simplesmente não existe.

Nota-se que as relações sociais são essenciais no desenvolvimento do juízo moral das crianças, e a analogia dos pequenos com os adultos e/ou com crianças mais velhas que exercem autoridade sobre eles está diretamente relacionada ao caráter sagrado e imutável que atribuem às regras (PIAGET, 1994). Dessa forma, compreende-se que o respeito estabelece um sentimento que contribui essencialmente para a aquisição das noções morais.

Em Kohlberg (apud BIAGIO, 2002), o desenvolvimento moral se dá em seis estágios, divididos em três níveis. Não obstante, a fim de manter-se o foco em uma determinada faixa etária, descrever-se-á apenas o nível pré-convencional ${ }^{2}$, que compreende basicamente as crianças menores de nove anos. Esse nível inicia-se com o primeiro estágio, que é a orientação para a punição e a obediência. Conforme descreve Kohlberg (citador por BIAGIO, 2002, p. 24), “[...] a ordem sociomoral é definida em termos de status de poder e de posses, em vez de o ser em termos de igualdade e reciprocidade". Fica, pois, claro que, para a criança, a moralidade está relacionada às causas e aos efeitos de suas ações: punição por um ato moralmente incorreto e a ausência desta no caso de um ato moralmente correto.

${ }^{2}$ Os demais níveis estão relacionados à adolescência e ao indivíduo adulto. 
Dossiê: Diálogos interdisciplinares em Psicologia da Educação

|Família e escola: parceiras no desenvolvimento moral das crianças |

| Rosana Mendes de Matos Privado | Neusani Oliveira Ives-Felix |

No segundo estágio do nível pré-convencional, o ato moralmente correto está relacionado ao prazer ou à necessidade pessoal, denominado "hedonismo", e a noção de "[...] igualdade e a reciprocidade emergem como "olho por olho, dente por dente" (BIAGIO, 2002, p. 25). O referido estágio é caracterizado como egocêntrico, em virtude de a criança compreender que a moral é circunstancial.

Em suma, observa-se que, para Kohlberg (apud BIAGIO, 2002) e Piaget (1994), a autoridade faz-se bem delineada em crianças com faixa etária entre 3 e 5 anos, uma vez que seu comportamento moral está intimamente ligado à reprodução das regras, embora ainda prevaleça a satisfação de suas próprias necessidades. Esse entendimento delimita o que Piaget (1994) denominou de "realismo moral", caracterizado pela consideração dos deveres e valores como algo intrínseco à criança, pois lhe são impostos de forma obrigatória e independem da consciência.

O realismo moral apresenta três características básicas: o cumprimento do dever é totalmente heterônomo, isto é, a regra não está ligada a uma interpretação consciente, é imposta à criança e adquire configuração aceitável quando a ação precede à obediência. A segunda característica configura a literalidade da regra e a terceira atrela-se à responsabilidade, em conceber as normas de forma precisa (PIAGET, 1994).

No entanto, tanto para Piaget (1994) quanto para Kohlberg (BIAGIO, 2002), a finalidade não é instituir a consciência moral arbitrariamente. Pelo contrário, o cumprimento do dever precisa se dar de forma autônoma, através do exercício da cooperação, que é fruto do respeito mútuo.

\footnotetext{
O respeito constitui o sentimento fundamental que possibilita a aquisição das noções morais. Duas condições, diz M. Bovet, são necessárias e suficientes para que se desenvolva a consciência de obrigação: em primeiro lugar que um indivíduo dê conselhos a outro e, em segundo lugar, que esse outro respeite aquele de quem emanam os conselhos (BOVET apud PIAGET, 1996, p. 77).
}

Nessas condições, faz-se imperativo afirmar que o respeito da criança para com seus pais ou professores é condição fundamental para que possa aceitar as diretrizes prescritas. Respeitar, de acordo com Bovet (apud PIAGET, 1996), é um sentimento nutrido pela pessoa e não pela regra em si. Dito de outro modo, é suficiente que a criança respeite o indivíduo, independente da regra imposta, relação essa iniciada nas estruturas mentais que possui e ao longo do processo de desenvolvimento, firmado por meio do relacionamento que tem com os adultos à sua volta. 
Dossiê: Diálogos interdisciplinares em Psicologia da Educação

|Família e escola: parceiras no desenvolvimento moral das crianças |

| Rosana Mendes de Matos Privado | Neusani Oliveira Ives-Felix |

Piaget (1996, p. 4) advoga que o respeito, enquanto unidade, subdivide-se em dois tipos: primeiro, o respeito unilateral, determinado por questões hierárquicas. Há aquele que respeita e aquele que é respeitado, dentro de uma relação coercitiva. Existe, também, o respeito qualificado, caracterizado pela ausência da coercitividade e imperado pela relação cooperativa, em que a essencialidade é o diálogo e a sinceridade.

Esses dois tipos de respeito, como reafirma Bovet (apud PIAGET, 1996), conduzem as crianças a dois comportamentos distintos. O primeiro é a coação moral, exercida pelo respeito unilateral, que resulta no sentimento de dever. É arbitrário e heterônomo. O segundo são as relações cooperativas, que, alicerçadas no respeito mútuo, produzem um sentimento de fazer o bem, de forma consciente, inteiramente autônoma.

O relacionamento não apenas impositor, mas construtor de uma afinidade baseada no respeito mútuo e na cooperação, auxilia para que as normas, inicialmente impostas às crianças, sejam aceitas e acatadas. Como consequência, tais relacionamentos podem culminar em uma tomada de decisão consciente, levando os pequenos a considerar as regras acima do seu eu.

É incontestável que pais e professores almejam ver seus pequenos crescendo rumo à felicidade, todavia é importante enfatizar que

[...] ninguém, ao vir ao mundo, sabe o que é certo e o que é errado. O ser humano, ao nascer, não tem ainda uma ética definida. E somos nós [pais e professores] que temos esta tarefa fundamental e espetacular - passar para as novas gerações esses conceitos tão importantes e que conferem ao homem sua humanidade (ZAGURY, 2010, p. 14).

Por isso, fundamental se faz atuar como mediador do processo educacional da criança no que diz respeito ao desenvolvimento moral, garantindo que o seu futuro seja de atuação social consciente, não perpetuando práticas desrespeitosas, tão comuns em nosso meio e tão desastrosos para a sociedade.

E como considerar as crianças que vão contra tudo e todos? Com relação ao dever moral, Piaget (apud LA TAILLE, 1992) levou-nos a compreender que a criança aprende através da imposição de regras dadas pelos pais e adultos que estão à sua volta, adentrando no universo moral. Porém, assim como há aceitação inquestionável dos preceitos morais, poderá ocorrer também a sua deformação.

A esse respeito, Montoya (2004) destaca o valor da experiência, a fim de compreender o significado da disciplina, da responsabilidade e da solidariedade, ações importantes para a construção de um indivíduo moralmente aceito. A escola ativa, real, 
precisa diariamente expor a criança a situações que a façam estar em contato direto com tais valores.

Convém, no entanto, lançar mão da assertiva de Durkheim (apud MUNARI, 2010, p. 51) sobre a construção da moralidade pautada em ações autônomas. Segundo esse autor, "a autonomia se adquire graças a um ensino que faz a criança compreender a natureza da sociedade e o porquê das regras morais". Sendo assim, não basta impor regras e limites, mas faz-se imprescindível explicar aos pequenos os "porquês" envolvidos no processo.

Reforçando a importância do desenvolvimento autônomo frente às regras, o Referencial Curricular Nacional para a Educação Infantil considera as crianças como indivíduos com capacidades e competências para construir conhecimentos e atuarem efetivamente no meio em que vivem. Com práticas que fortalecem o autogoverno em situações concretas, paulatinamente o farão no plano das ideias e dos valores (BRASIL, 1998).

Sob esse viés, pais e professores precisam fazer o possível para tornarem-se colaboradores no desenvolvimento moral dos infantes, valorizando o respeito mútuo como forma de equilibrar o relacionamento entre adultos e crianças. Compreendê-las e respeitálas fazem parte do processo de reciprocidade, e a criança não estará apenas num invólucro de normas, mas, muito além disso, numa teia de relações sociais baseada em respeito recíproco (MUNARI, 2010; PIAGET, 2002).

Na mesma linha de pensamento, Sampaio (2007) afirma que a concepção do espaço educacional como promotor de diálogo, repensando a própria moralidade, é um valioso ponto de partida, daí a necessidade de redefinir seus objetivos e fortalecer a psicologia educacional.

Para Kohlberg (1971, apud BIAGIO, 2002), a educação moral está fundamentada na ligação social, no cuidado com os outros e com o grupo, e é reafirmada com os métodos "ativos" desta, quando a criança é levada a vivenciar suas próprias experiências morais, sendo a escola uma ponte para tais experiências.

De fato, a parceria entre escola e família, em prol de instruir as crianças sobre respeito, normas e valores, é estar investindo na educação moral dos infantes. Logo, para que se compreenda melhor esse trabalho conjunto, apresenta-se a pesquisa de campo realizada na Pré-Escola Aurila Barros, localizada no Município de Grajaú/MA.

\section{A educação moral na relação família e escola: a percepção dos professores da Pré-}

Escola Aurila Barros sobre noções morais 
Dossiê: Diálogos interdisciplinares em Psicologia da Educação

|Família e escola: parceiras no desenvolvimento moral das crianças |

| Rosana Mendes de Matos Privado | Neusani Oliveira Ives-Felix |

Com o objetivo de levantar informações junto aos professores, sobre como o relacionamento com seus alunos tem contribuído com o desenvolvimento do juízo moral dos infantes, aplicou-se uma entrevista àqueles que estavam atuando em sala de aula.

Tendo em vista os objetivos propostos na pesquisa, que são relatar as noções que os professores têm acerca do respeito enquanto sentimento essencial, que permite a obtenção de noções morais, e analisar os procedimentos utilizados por eles na educação moral das crianças, buscaram-se as informações junto a três professoras, que atuam na escola nos turnos matutino e vespertino ${ }^{3}$.

Inicialmente, indagou-se às professoras a relação que têm com os pais de seus alunos e se eles contribuem efetivamente com a escola no que diz respeito à formação moral das crianças. A professora $\mathrm{A}$ iniciou a discussão comentando:

[...] nós temos a contribuição de muitos pais, mas têm aqueles pais que a gente tem até medo de falar da criança, porque quando a criança chega em casa faltam é matar as crianças de bater e não resolve o problema, chega no dia seguinte a criança está do mesmo jeito. Quando a criança apronta ela já fala 'tia não fala pra minha mãe', então já vejo no olhar da criança medo. Então eu tento resolver por aqui, e não tenho mais coragem de pedir ajuda. ${ }^{4}$

A professora B relatou também um fato ocorrido em sua turma:

Eu tenho um aluno no infantil I (criança de quatro anos), que foi inserido na minha turma alguns meses depois do início do ano, e a turma já estava com o comportamento exemplar, e quando ele chegou, ele batia em um, mordia o outro, e aquela coisa. Mas durante o processo de adaptação com a turma eu fui conversando com ele e orientei a mãe dele a conversar em casa com ele também. Um dia ele chegon e me mostron a orelha machucada, en perguntei se ele havia caído, e ele disse 'não a senhora falou para a mãe que eu bati no colega e ela me bateu'. Aquilo pra mim foi o fim [...]. Eu consegui que ele não agredisse mais os colegas, mas foi conversando aqui mesmo e mostrando pra ele como os colegas se comportavam.

A Professora C comenta sobre um fato ocorrido com a mãe de um de seus alunos de três anos:

Tem aqueles casos que a mãe chega e diz que o filho tá pra deixar ela doida. Eu tenho um caso assim, onde a menina tem dificuldade de comportar-se e ai fui conversar com a mãe, ela disse pra mim que não sabe nem o que fazer com a filha dela. Então eu vi que ela havia perdido o domínio sobre a filha dela, a menina não tem limites.

Em uma reunião de pais e mestres, a professora B relata um comentário que dividiu com os pais:

\footnotetext{
${ }^{3}$ A escola estava com desfalque de dois professores, em razão de problemas de contratação ligados a questões de ordem administrativa da Secretaria de Educação.

${ }^{4}$ Os comentários são uma transcrição literal da fala dos entrevistados, não se fazendo qualquer correção quanto a aspectos gramaticais da língua, principalmente porque a fala é espontânea e natural, não se prende a regras e padrões como a escrita.
} 
Dossiê: Diálogos interdisciplinares em Psicologia da Educação

| Família e escola: parceiras no desenvolvimento moral das crianças |

| Rosana Mendes de Matos Privado | Neusani Oliveira Ives-Felix |

Eu falei para eles na reunião de pais: gente vocês com uma criança, vocês chegam pra gente e dizem que não dominam mais, não sabe mais o que fazer e nós pegamos vinte crianças, e nós não podemos bater e nós conseguimos dominar eles sem essa necessidade de bater, vocês batem e não resolve nada. Então tá faltando chegar e conversar com elas, tá faltando vocês sentarem e ajudar a criança $[\ldots]$.

Nesses casos relatados, são evidentes que os pais apelam tão somente para a coação, sublinhando o respeito unilateral. Não há aqui a intenção de julgar os procedimentos que a família utiliza para corrigir os pequenos, mas mostrar como é a educação moral nos dias de hoje.

La Taille (1992, p. 15) focaliza a importância da justiça, assim, para esse autor, "[...] a cada momento, deve-se decidir como fazer justiça, e, no mais das vezes, não existem procedimentos precisos para que se alcance o intento: deve-se, justamente, avaliar, pesar, interpretar as diversas situações e então decidir o que fazer".

Sobre o autoritarismo dos pais, Zagury (2010, p. 19-20) afirma:

[...] a palmada não resolve absolutamente os problemas da relação. Aparentemente pode até resolver, porque em um primeiro momento faz com que a criança se sinta amedrontada e recue. Por outro lado, [...] mesmo apanhando e com medo, a criança que se sente extremamente agredida [...] encontra forças para enfrentar os pais dizendo, por exemplo, "não doeu", "viu, nem chorei" e coisas do gênero.

A escola necessita do apoio dos pais sempre, porém estes, na maioria das vezes, acabam recorrendo à punição física quando recebem queixas do mau comportamento de seus filhos. Os professores, para evitar tais questões, acabam por não compartilhar com a família os acontecimentos da sala de aula, e nesse momento a escola acaba por assumir responsabilidades que deveria contar com a instância familiar.

Interpelou-se às docentes quanto às práticas vivenciadas em sala de aula relacionadas ao respeito. A professora B iniciou os comentários afirmando que "boje houve uma certa mudança. No primeiro ano que a gente trabalhou aqui, as crianças costumavam falar termos obscenos, palavrões [...], hoje em dia é raro ouvir uma criança dizer isso aqui. Deve haver uma ou duas, mas como era antes não".

O mesmo se passa na turma das crianças de 4 anos, pois, consoante a professora A:

Na prática é muito diálogo, conversa. É o nosso diálogo do dia a dia ... quando eles estão muito agressivos uns com os outros, e eu falo vocês já viram as tias se batendo, empurrando? Não! Eu dou exemplo de nós mesmas, para eles se espelharem em nós[...]. Esses dias eu tenho usado muito os combinados, e quando eu olho para o mural eles já sabem o que quero dizer. 
Dossiê: Diálogos interdisciplinares em Psicologia da Educação

| Família e escola: parceiras no desenvolvimento moral das crianças |

| Rosana Mendes de Matos Privado | Neusani Oliveira Ives-Felix |

O comportamento das crianças, ao longo dos anos, encontra respaldo em Motoya (2004, p. 178) quando este ressalta que:

[...] um ritual é imposto a uma criança pelos adultos ou pelos mais velhos respeitados por ela (Bovet), ou desde que um ritual resulte da colaboração de duas crianças (Piaget), ele adquire para a consciência do indivíduo um caráter novo, que precisamente é aquele da regra.

Fica, pois, claro que o relacionamento professor/aluno e aluno/aluno, com efeito, está permeado de vivências positivas. E, mesmo frente a ações não aceitáveis, é possível fazer destas um momento de aprendizado, confrontando na prática o certo e o errado, o aceitável e o não aceitável, o bem e o mal.

Ao serem investigadas sobre a rotina desenvolvida na sala de educação infantil e a relação deste com a cooperação em classe, a professora A comentou que "[...] quando eles chegam aqui, eles querem logo brincar, ai eu vou explicar o que vai acontecer naquele dia e que temos horário pra tudo. Então, eles já estão acostumados a seguir aquela rotina, mesmo que tem uns que querem pular etapas". A Professora C, que trabalha com as crianças de três anos, diz que "no início dá mais trabalho, mas eles vão se adequando... e eles já sabem o que vem em seguida [...]”.

Com relação à prática educacional, vale ressaltar a fala de Kohlberg (apud BIAGIO, 2002, p. 71), quando defende as práticas democráticas e salienta que a importância da “[...] ligação social, o cuidado com os outros e com o grupo são fundamentais para a educação moral". Em outras palavras, o envolvimento do grupo (crianças e professores) para a consecução das atividades reforça a noção de responsabilidade de todos para com as ações da coletividade.

Com o intuito de colaborar com o desenvolvimento moral das crianças em parceria com a família, a escola tem colocado em prática o Projeto Semeando Valores. O referido projeto é de autoria da escritora Ana Maura Tavares dos Anjos e foi adotado pela Secretaria Municipal de Educação do Município de Grajaú, em uma parceria com a Editora IPDH. O projeto almeja colaborar significativamente para o fortalecimento dos vínculos familiares entre crianças, pais ou outros responsáveis (ANJOS, 2014).

Quando sondadas sobre os efeitos do projeto na escola e na família, a professora C comentou que "[...] não é que as crianças não tenham noção dos valores trabalhados, todos esses valores são trabalhados em casa, mas eu tenho observado que ele tem contribuído muito, ele tem melhorado e vão melhorar ainda mais".

Tal prática reforça o entendimento de que a instituição escolar deve auxiliar a criança a desenvolver-se moralmente, propondo, em consonância com a família, momentos 
Dossiê: Diálogos interdisciplinares em Psicologia da Educação

|Família e escola: parceiras no desenvolvimento moral das crianças |

| Rosana Mendes de Matos Privado | Neusani Oliveira Ives-Felix |

de discussões dos dilemas morais, utilizando-se de diversos recursos a fim interagir e buscar soluções para problemas vivenciados na esfera social.

Finalizando a pesquisa direcionada aos educadores, perguntou-se que tipo de trabalho é desenvolvido em sala para estimular a autonomia das crianças, em relação à rotina que é trabalhada, aos combinados e à repreensão de um colega que está infringindo as regras. A professora $\mathrm{B}$ discorre que tudo está relacionado à confiança que os educadores transmitem, instigando o desenvolvimento da autoconfiança das crianças

[...] eu tenho uma criança à tarde, [...] se eu sentar perto dela e quando eu falo com ela, ela já se treme toda. Aquela criança eu não sei como ela é tratada em casa, mas eu sei que aqui na escola eu tenho que passar confiança pra ela. Para os outros eu já consegui passar confiança pra que eles tenham autoconfiança, confiar neles mesmos pra realizar as ações.

Enfim, por meio de todas as falas das docentes, é notória a necessidade, e urgência, de uma formação moral, e a escola tem papel fundamental na educação, visando à moralidade e à promoção de juízos morais que gerem justiça, altruísmo, solidariedade, respeito ao próximo, a si mesmo e a toda forma de vida que exista sobre a face da terra (BIAGIO, 2002).

\section{Relação família e escola: o desafio da educação moral}

Com o intento de analisar os procedimentos utilizados pelos pais na educação moral dos infantes e relatar as noções que os pais possuem sobre o respeito enquanto sentimento essencial, que permite a obtenção de noções morais, bem como compreender como se dá o relacionamento família e escola, e como ambas se posicionam frente ao desenvolvimento moral dos pequenos, foram entrevistados 20 pais, que totalizaram $25 \%$ do universo total de responsáveis vinculados à escola.

A primeira pergunta direcionada aos pais foi se eles visualizavam as contribuições que a escola tem agregado ao desenvolvimento moral das crianças que ali frequentam. Cem por cento $(100 \%)$ dos entrevistados afirmaram que sim, justificando que conseguem observar progressos efetivos no desenvolvimento moral de seus filhos.

Alguns relatos realçam essa parceria. Segundo um dos pais entrevistados, denominado entrevistado A, "[...] a educação vem de casa, mas a escola contribui muito [...] pois meu menino é um pouco sapeca". Outro entrevistado, E, relata-nos: "[...] ele estudando aqui ele tem mais educação, porque quando ele chega lá em casa ele não me respeita, mas aqui ele respeita o professor".

Conforme já afirmado, a finalidade deste estudo não é, de forma alguma, julgar a posição dos pais, que, tanto para Piaget (1994) quanto para Kohlberg (apud BIAGIO, 
Dossiê: Diálogos interdisciplinares em Psicologia da Educação

|Família e escola: parceiras no desenvolvimento moral das crianças |

| Rosana Mendes de Matos Privado | Neusani Oliveira Ives-Felix |

2002), representam a primeira relação das crianças, são os adultos que servem tanto de modelo para a imitação de algumas ações, quanto quem lhes impõe as regras. A noção de respeito está intimamente ligada à visão que as crianças têm de seus pais, elas não nascem moralmente corretas ou incorretas, mas a moral é algo alcançado através das relações sociais vivenciadas.

Cotidianamente, a fala dos pais está permeada de expressões como "não sei mais o que fazer", "meu filho não me obedece mais". Tais expressões resultam da falta de limites quando as crianças ainda estão com idade entre 2 a 6 anos, vistas como imaturas para compreender seus direitos e o dos outros, ouvir o não quando necessário e o sim quando possível. Além disso, os pais terminam não sendo o exemplo vivo dos princípios que pregam, uma vez que a máxima "faça o que eu digo, mas não faça o que eu faço" não deveria ser uma lógica a ser seguida por ninguém.

Perguntou-se aos pais se eles se viam aptos a contribuir com a formação moral de seus filhos. Oitenta e cinco por cento (85\%) afirmaram estar aptos a contribuir com a formação moral dos seus filhos, enquanto $15 \%$ dos entrevistados julgaram-se não possuidores de capacidade para contribuir com a formação moral de seus filhos. Vale ressaltar a fala do entrevistado D, que diz "[...] en fico bem preocupada, tanto coisa ruim acontecendo [...] é bem complicado. A gente se sente segura em contar com a escola".

As declarações, em parte, refletem a realidade vivenciada atualmente, porquanto inúmeras crianças praticam ações que assombram a sociedade, como não respeitar a hierarquia familiar, não saber receber um não e ser extremamente egocêntrica.

Os pais precisam acreditar em si mesmos para educarem seus filhos, e isso só ocorre quando se determinam limites na vida da criança, a fim que "[...] inicie o processo de compreensão e apreensão do outro" (ZAGURY, 2010, p. 13). Dessa forma, vivenciar os limites não imprime traumas psicológicos, mas leva as crianças a compreender que na vida não se pode fazer tudo o que se deseja, pois há regras e normas na sociedade, e desobedecer a elas pode trazer sérias consequências, seja pessoais, seja sociais, seja legais.

$\mathrm{Na}$ terceira pergunta da entrevista, questionou-se aos pais os procedimentos utilizados por eles para corrigir as crianças nos casos de ações indesejadas. Vinte e cinco por cento (25\%) recorrem ao castigo, 30\% batem e $45 \%$ corrigem através da conversa. De acordo com alguns entrevistados, a mudança de postura quanto ao método é frequente, como a entrevistada B, que afirmou "[...] eu era mais bruta com ele, batia nele, en falava e ele não me ouvia. Agora não, eu 'tô' tentando ver se ele consegue me ouvir [...]”. Não há dúvidas da eficácia da coerção para o início da educação moral, de sua necessidade, além de ser uma ação 
Dossiê: Diálogos interdisciplinares em Psicologia da Educação

|Família e escola: parceiras no desenvolvimento moral das crianças |

| Rosana Mendes de Matos Privado | Neusani Oliveira Ives-Felix |

inevitável, mas é preciso que, em um dado momento, ela dê espaço para a autonomia, o diálogo e o respeito mútuo.

Voltando a falar do autoritarismo, Zagury (2010, p. 93) traz a lume algumas justificativas interessantes sobre o não uso da agressão física:

[...] bater não resolve o problema da relação[...], bater de leve pode levar a bater para valer, [...], o ato de bater redunda, para os pais, num sentimento terrível de desapontamento consigo mesmo, gerando muita culpa [...]. Podemos concluir que a palmada não resolve coisa alguma, a não ser criar uma situação que, pouco a pouco, pode afastar severamente pais e filhos.

Conforme se depreende, é de extrema importância que o diálogo entre pais e filhos seja uma constante; é uma prática que requer paciência, naturalidade e carinho acima de tudo. Compreender os seus limites é algo que as crianças não aprendem do dia para noite, mas, a partir de práticas que incentivem os pequenos a assumirem seus atos, fazendo-os refletir sobre as atitudes incorretas, antiéticas ou egocêntricas.

Concluindo essa parte da entrevista, os pais foram indagados se há observação de melhorias no desempenho moral dos pequenos com relação aos temas já trabalhados pelo Projeto Semeando Valores. Todos foram enfáticos em tecer elogios sobre a ação do projeto. Na verdade, essa tem sido uma prática validada tanto por Piaget (1994) quanto por Kohlberg (apud BIAGIO, 2002) no concernente às práticas morais no âmbito educacional, levando as crianças não apenas a obedecerem, mas também a refletirem sobre as ações aceitas no meio em que estão inseridas.

Em suma, como se pôde analisar, a participação de cada sujeito envolvido nesta pesquisa foi importante. Observou-se uma preocupação central, que é a inquietude referente à formação moral dos pequenos, indivíduos que, hoje, se encontram em formação, mas que, futuramente, estarão ocupando mais ativamente o seu lugar na sociedade.

\section{CONSIDERAÇÕES FINAIS}

As investigações psicológicas sobre a moralidade têm apresentado efetiva evolução ao longo dos anos, favorecendo sobremaneira a compreensão dos processos envolvidos na vida em sociedade. Partindo de teorias psicológicas como as de Piaget e Kohlberg, vêm-se desenvolvendo estudos visando ao desenvolvimento social e moral de crianças, principalmente das em idade pré-escolar. 
Dossiê: Diálogos interdisciplinares em Psicologia da Educação

|Família e escola: parceiras no desenvolvimento moral das crianças |

| Rosana Mendes de Matos Privado | Neusani Oliveira Ives-Felix |

Este tipo de estudo se faz pertinente para que haja uma reflexão sobre a realidade e esclarecimentos essenciais para pais e educadores compreenderem seu real papel na constituição moral dos pequenos, bem como sensibilizá-los quanto a sua efetiva importância na construção de um indivíduo capaz de atuar autonomamente na sociedade.

Após versar sobre o tema em questão, em síntese família e escola, cada uma a seu modo, contribuem para o desenvolvimento de juízo moral nas crianças que estão sob seus cuidados. Entretanto, vale ressaltar que a família, mesmo tentando superar uma postura autoritária na criação de seus pequenos, ainda encontra dificuldades em instituir regras e valores pautados em uma educação menos arbitrária e mais dialógica.

A propósito, isso não quer dizer que a conclusão acerca dos depoimentos é pessimista. A mudança de comportamento frente a uma educação de imposições é notável. Muitos pais abdicaram daquele tipo de educação com a qual foram criados. Mas é necessário agir com segurança e firmeza, com amor e carinho, ter autoridade sem autoritarismo, ou seja, é saber estabelecer os limites do que pode e o que não pode ser feito, levando em consideração o que o outro pensa. Resumindo, é imprescindível que a família se encontre e tenha mais cuidados e atenção no que diz respeito ao desenvolvimento moral de suas crianças.

Da mesma forma, a escola precisa atuar considerando a criança como ser pensante, levando-a a refletir sobre os seus atos e quais posturas são corretas na convivência com os colegas. O educador precisa ter sempre claro o que deseja das crianças, que comportamentos e ações são permitidos, ou não, dentro e fora da sala de aula, como gostaria de ser tratado e da mesma forma tratar os seus iguais e os mais velhos.

O comportamento que se espera não se apresenta instantaneamente, é algo que precisa ser cultivado dia após dia, levando a criança a considerar sempre os seus direitos e o dos outros, as possibilidades do "não", o que pode e não pode ser feito, a importância de saber conviver. Os profissionais da educação devem ter sempre em mente, sobretudo, que os infantes aprendem através do exemplo, e que ditados como "faça o que eu digo, mas não faça o que eu faço" não é considerado pelas crianças; o ato em si é sempre copiado.

Observou-se, na pesquisa, a preocupação de pais e educadores com o desenvolvimento moral dos pequenos. Os métodos utilizados pelos progenitores são inúmeros, vão da conversa à força física. Nesse sentido, à escola cabe observar como as crianças reagem quando são corrigidas e, em diálogo com os responsáveis e as crianças, devem tentar desvendar como é a educação familiar. 
Dossiê: Diálogos interdisciplinares em Psicologia da Educação

|Família e escola: parceiras no desenvolvimento moral das crianças |

| Rosana Mendes de Matos Privado | Neusani Oliveira Ives-Felix |

Dessa maneira, a escola pode contribuir, mas jamais substituir a família, a qual precisa dar limites às suas crianças, para que ações como descontrole emocional, dificuldades em aceitar limites, distúrbios de conduta, falta de respeito, incapacidade de concentração, agressões físicas sejam evitados. Consequentemente, as crianças podem crescer responsáveis e atuantes no meio social em que estão inseridas.

A pesquisa demonstrou que família e escola devem agir em conjunto, a fim de que as crianças sejam respeitadas, mas que, principalmente, elas possam encontrar nos adultos a segurança da autoridade que lhes é confiada, carregando sempre o respeito mútuo e o estímulo à cooperação.

O que se espera, na grande jornada educacional das crianças, é que cresçam felizes, responsáveis, conscientes de seus direitos e deveres, comprometidos com o desenvolvimento de uma sociedade justa, pacífica e igualitária. Isto é, espera-se sua formação cidadã, papel precípuo da escola.

\section{REFERÊNCIAS}

ANJOS, Ana Maura Tavares dos Anjos. Semeando valores: construindo valores na escola e na família. Fortaleza: Edições IPDH, 2014.

BIAGIO, Ângela Maria Brasil. Lawrence Kohlberg: ética e educação moral. São Paulo: Moderna, 2002.

BRASIL. Referencial curricular nacional para a educação infantil. Brasília: MEC/SEF, 1998.

LA TAILlE, Yves de; OLIVEIRA, Marta Kohl de; DANTAS, Heloysa. Piaget, Vygotsky, Wallon: teorias psicogenéticas em discussão. São Paulo: Summus, 1992.

MONTOYA, Adrián Oscar Dongo. Contribuições da psicologia e epistemologia genéticas para a educação. In: CARRARA, Kester (Org.). Introdução à psicologia da educação: seis abordagens. São Paulo: Avercamp, 2004.

MUNARI, Alberto. Jean Piaget. Recife: Fundação Nabuco; Editora Massangana, 2010.

NEVES, Eduardo Borba; DOMINGUES, Clayton Amaral (Org.). Manual de metodologia da pesquisa científica. Rio de Janeiro: EB/CEP, 2007.

PIAGET, Jean [1932]. O juízo moral na criança. Tradução de Elzon Lenardon. São Paulo: Summus, 1994.

PIAGET, Jean. Os procedimentos da Educação Moral. Tradução de Maria Suzana de Stefano Menin. In: LINO, Marcedo (Org.). Cinco estudos de educação moral. São Paulo: Casa do Psicólogo, 1996. p. 01-36. 
Dossiê: Diálogos interdisciplinares em Psicologia da Educação

| Família e escola: parceiras no desenvolvimento moral das crianças |

| Rosana Mendes de Matos Privado | Neusani Oliveira Ives-Felix |

SAMPAIO, Leonardo Rodrigues. A psicologia e a educação moral. Psicologia: Ciência e Profissão, Brasília, v. 27, n. 4, dez. 2007. Disponível em: $<\underline{\text { http: }}$ / www.scielo.br/scielo.php?script=sci arttext\&pid=S1414-98932007000400002>. Acesso em: 31 ago. 2015.

ZAGURY, Tania. Limites sem trauma: construindo cidadãos. 86. ed. Rio de Janeiro: Record, 2010. [recurso eletrônico].

Educar sem culpa: a gênese da ética. Rio de Janeiro: Record, 2011. [recurso eletrônico]. 